\title{
Alerginis alveolitas
}

\author{
Brigita Šitkauskienė \\ LSMU MA Pulmonologijos ir imunologijos klinika
}

Reikšminiai žodžiai: alerginis alveolitas, hipersensityvinis pneumonitas.

Santrauka. Alerginis alveolitas (dar vadinamas hipersensityviniu pneumonitu) yra difuzinè instersticinè plaučių liga, kurią sąlygoja padidèjęs jautrumas j̇kvepiamoms organinių antigenų dalelèms. Straipsnyje apžvelgiami klinikinejje praktikoje aktualūs alerginio alveolito diagnostikos ir gydymo aspektai.

Alerginiu alveolitu susergama ịsijautrinus kartotinai ¡̇kvepiamomis dalelėmis, kuriụ sudètyje yra organinių antigenų. Užsienio literatūroje alerginis alveolitas gana dažnai vadinamas hipersensityviniu pneumonitu (angl. hypersensitivity pneumonitis), o anksčiau dar buvo vadinamas išoriniu (egzogeninių) alergenų sukeltu alveolitu (angl. extrinsic allergic alveolitis). Alerginis alveoli- tas dar gali būti ịvardijamas ịvairiausiai - tai priklauso nuo ligą provokuojančio veiksnio (1 lentelè).

\section{EPIDEMIOLOGIJA}

Alerginio alveolito epidemiologija nèra gerai žinoma. Gan dažni atvejai, kai ši liga nediagnozuojama, ypač

1 lentelè. Alerginio alveolito tipas pagal provokuojamaji (etiologini) veiksni

\begin{tabular}{|c|c|c|}
\hline Tipas & Specifinis antigenas & Ekspozicija \\
\hline $\begin{array}{l}\text { „Balandžiu męgèjo (augintojo) plaučiai“" arba } \\
\text { „paukštyno darbuotojo plaučiai“ }\end{array}$ & Paukščio baltymai & Plunksnos ir paukščių išskyros \\
\hline „Fermerio plaučiai“ & $\begin{array}{l}\text { Pelèsiniai grybeliai: } \\
\text { - Thermophilic actinomycetes } \\
\text { - } \quad \text { Aspergillus } \\
\text { - } \quad \text { Saccharopolyspora rectivirgula } \\
\text { - Micropolyspora faeni }\end{array}$ & Suplèkęs šienas \\
\hline „Kokaino plaučiai“ & Kokainas & Intensyvus kokaino rūkymas \\
\hline „Salyklo gamintojo plaučiai“ & Aspergillus clavatus & Apipelèję miežiai \\
\hline „Klevo žievès liga“ & Cryptostroma corticale & Apipelèjusi klevo žievè \\
\hline „Durpyno darbuotojo plaučiai“ & Monocillium sp. ir Penicillium citreonigrum & Durpès, kerpès \\
\hline „Malūnininko plaučiai“ & Sitophilus granarius & Dulkèmis užteršti grūdai \\
\hline „Komposto plaučiai“ & Aspergillus & Kompostas \\
\hline "Grybų augintojo plaučiai“ & Thermophilic actinomycetes & Grybų kompostas \\
\hline Suberozè & Penicillum frequentans & Apipelèjusio kamščio dulkės \\
\hline „Sūrio plovèjo plaučiai“ & Penicillum casei ar P. roqueforti & Sūrio apvalkalai \\
\hline Metalo apdirbimo skysčių sukeltas pneumonitas & Netuberkuliozinès mikobakterijos & Metalo apdirbimo skysčiụ dulksna, garai \\
\hline Beriliozè & Berilis & Elektronikos pramonè \\
\hline $\begin{array}{l}\text { Trimetilo anhidrido sukeltas pneumonitas arba } \\
\text { "Chemijos darbuotojo plaučiai“ }\end{array}$ & Trimetilo anhidridas & Plastmasės, gumos, dažai \\
\hline Isocianato sukeltas pneumonitas & $T D I, H D I, M D I$ & Dažai, dervos, poliuretano putos \\
\hline „Karštų katilų (kubilų) plaučiai“ & Mycobacterium avium kompleksas & Garai nuo karštų katilų \\
\hline „Vynuogių augintojo plaučiai“ & Botrytis cinerea & Apipelëjusios vynuogès \\
\hline
\end{tabular}




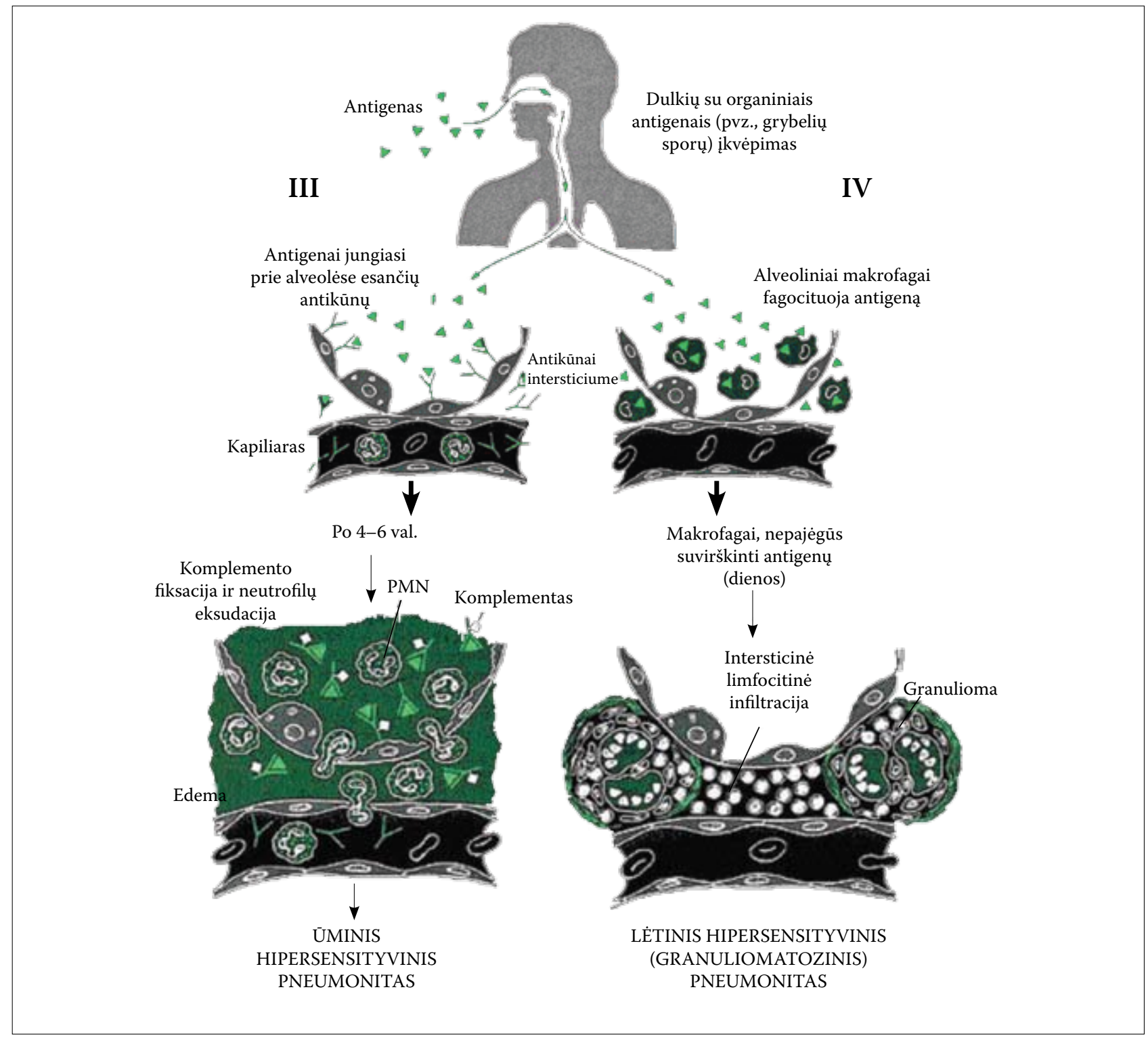

1 pav. Alerginio alveolito patogenezè (adaptuota pagal L. C. Mohr [2])

jei jos klinikiniai simptomai lengvi arba netipiniai, „pasislepia“ po virusinès infekcijos arba astmos diagnoze. Keli, anksčiau atlikti epidemiologiniai tyrimai parodè, kad „fermerio plaučiai“ yra viena dažniausių alerginio alveolito formų, ja serga 0,4-7 proc. ūkininkų. Ligos paplitimas įvairiuose regionuose labai skiriasi, priklauso nuo ūkininkavimo itpročių, klimato ypatybių (drègnose zonose alerginiu alveolitu rizikuoja sirgti apie 9 proc. ūkininku): JAV 420-3 000 atvejų 100 tūkst., Jungtinejje Karalystejje 12-2 300 atvejų 100 tūkst., Suomijoje 1400 1700 atvejų 100 tūkst. Dar dažniau alerginis alveolitas nustatomas paukščių mėgèjams: 20-20 000 atvejų 100 tūkst. per metus. Literatūroje aprašoma, kad alerginis alveolitas gana dažnas ir kitú profesijų asmenims: 37 proc. gelbètoju itakos turejo plaukimo baseino aplinka, 52 proc. biuro darbuotojų - oro drėkintuvai.

Atliekant tyrimus, pastebèta, kad rūkymas susijęs su mažesne rizika sirgti alerginiu alveolitu. Šis įdomus reiškinys aiškinamas taip: rūkymas ženkliai sutrikdo kvẻpavimo takų apsauginius mechanizmus, normalų imuninị atsaką, todèl sumažejja ir antikūnų prieš įkvepiamuosius antigenus gamyba.

\section{PATOGENEZE்}

Ilkvepiamasis antigenas sukelia audringą imunini atsaką: alerginis alveolitas pasireiškia III ar IV tipo hiperergine reakcija (1 pav.).

Daugejja duomenų, kad egzistuoja genetinè predispozicija sirgti alerginiu alveolitu, - nustatyta šios ligos pasireiškimo sąsaja su pagrindinio audinių suderinamumo komplekso (angl. major histocompatibility complex, MHC) II klasès specifiniais aleliais. Tiriant karvelių augintojus, sergančius alerginiu alveolitu, dažniau nustatomi žmogaus leukocitų antigenu (angl. human leucocyte antigens, HLA)-DRB1*1305 bei 
HLA-DQB1*0501 aleliai, rečiau HLA-BRB1*0802 alelis ir dažnesnis navikų nekrozès faktoriaus (TNF)-2 (-308) polimorfizmas.

\section{SIMPTOMAI}

Pagal simptomų pasireiškimo trukmę alerginis alveolitas skirstomas ị ūminị, poūmị ir lètinị.

Ūminio alerginio alveolito atvejais simptomai pasireiškia gana greitai - po 4-6 val. nuo kontakto su provokuojamuoju veiksniu (alergenu). Simptomai būna panašūs ị gripo: karščiavimas, galvos skausmas, sausas kosulys; sunkiais atvejais galimi ūminio kvėpavimo nepakankamumo reiškiniai. Nutraukus kontaktą su alergenu, simptomai išnyksta per 12 val., kartais - per keletą dienų.

Poūmès eigos atvejais alerginio alveolito simptomai pasireiškia palaipsniui. Jie būna panašūs ị lètinio bronchito simptomus: produktyvus kosulys, dusulys, svorio mažejimas. Poūmio alerginio alveolito simptomai paprastai būna lengvesni nei ūminio alerginio alveolito atvejais, bet trunka ilgiau.

Lètiniu alerginiu alveolitu sergantys ligoniai nepatiria ūmių epizodų, simptomai būna „užmaskuoti“. Pacientai skundžiasi progresuojančiu dusuliu, nuovargiu, svorio mažèjimu; dažnai nustatoma tachipnèja, respiracinis distresas, inspiracinè krepitacija.

\section{DIAGNOSTIKA}

Alerginio alveolito diagnostika paremta tipine anamneze (simptomai pasireiškia po kontakto su alergenu) ir klinikiniais tyrimais.

Kraujo tyrimas gali rodyti uždegimo reakcijai būdingus pokyčius (padidejęs leukocitų skaičius ir eritrocitų nusèdimo greitis, ypač ūminès ligos atvejais), pažymètina, kad eozinofilija nebūdinga.

Krūtinès ląstos rentgeniniu tyrimu patologinių pokyčių paprastai nerandama, kartai pastebima nespecifinių infiltracinių ir židininių pažeidimų. Kompiuterinejje tomogramoje dažnu atveju matoma plaučiuose difuziškai išplitusių smulkių, neaiškių ribų židinių, „matinio stiklo“ vaizdas, lètinio alerginio alveolito atvejais - fibrozinių ir cistinių plaučių parenchimos pokyčių (2 pav.).

Tiriant plaučių funkciją, alerginio alveolito atvejais nustatomas restrikcinio (rečiau mišraus) pobūdžio ventiliacinès funkcijos sutrikimas, sumažèjusi dujų difuzija.

Bronchoskopija alerginiu alveolitu sergantiems asmenims dažniausiai patologinių pokyčių nenustatoma, bet būdinga tai, kad histologiškai tiriant plaučiu audinio biopsinę medžiagą randama epiteoidinių ir gigantiškų daugiabranduolių ląstelių granuliomų be kazeozinès nekrozès požymių (3 pav.).

2010 metų UpToDate šaltinyje siūlomi šie alerginio alveolito diagnostikos kriterijai:

1. Patvirtinta priežastinio, ligos simptomus sukeliančio antigeno ekspozicija:

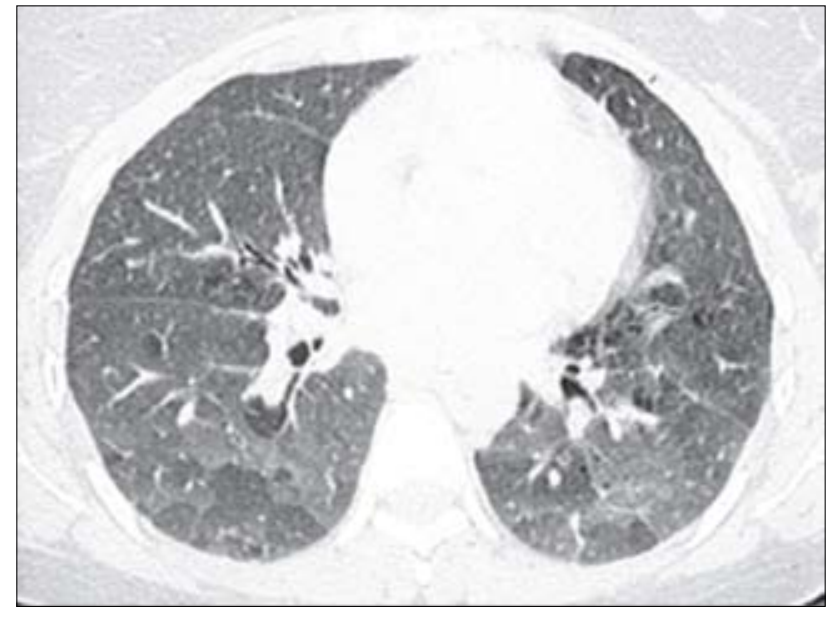

2 pav. Matinio stiklo vaizdas, būdingas ūminès eigos alerginiam alveolitui (pagal P. Stark [8])

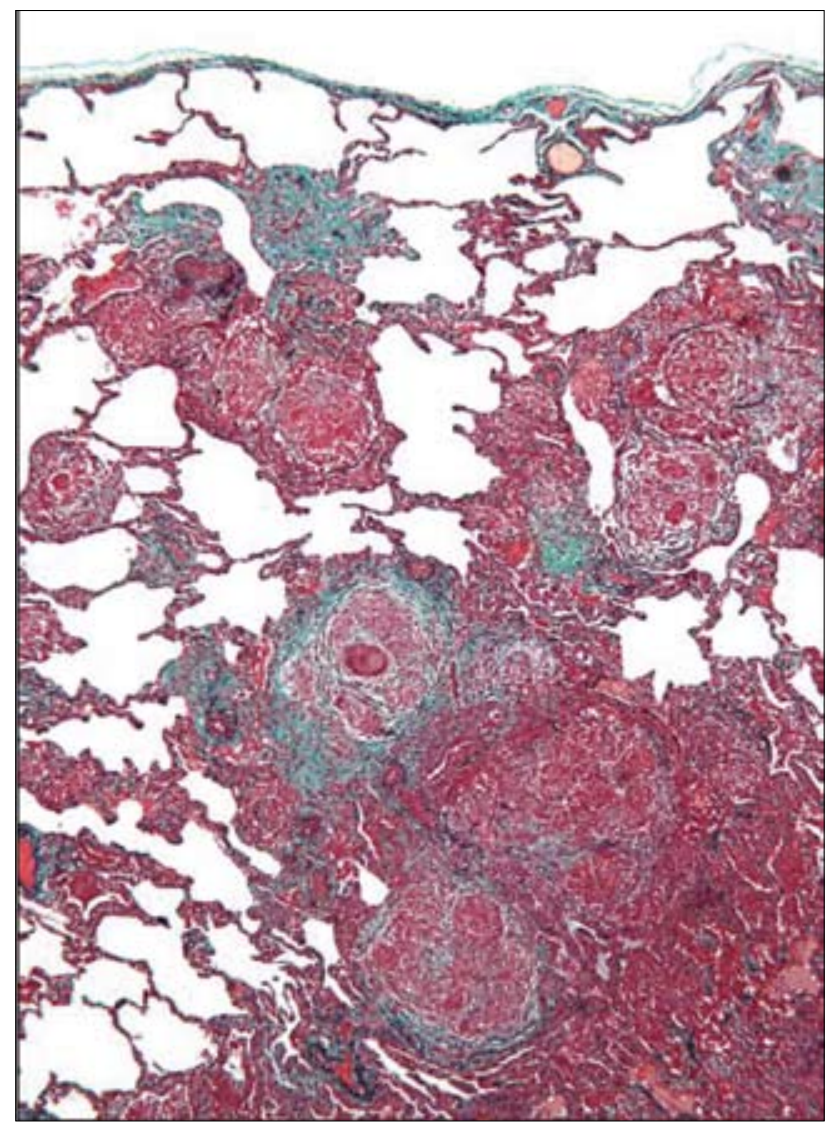

$\mathbf{3}$ pav. Alerginiu alveolitu sergančio ligonio plaučių audinio biopsijos histologinis tyrimas: lètiniam intersticiniam uždegimui būdingas vaizdas (limfocitų infiltracija, granuliomos be kazeozinès nekrozès požymių [8])

A. Atitinkama antigeninė ekspozicija anamnezėje. B. Aerobiologinis ar mikrobiologinis aplinkos tyrimas, patvirtinantis antigeno buvimą.

C. Specifinių IgG antikūnų serume nustatymas.

2. Būdingi klinikiniai, radiologiniai ar fiziologiniai požymiai:

A. Kosulys, dusulys (ypač po kontakto su antigenu), svorio mažéjimas ir pan. 
B. Matinio stiklo vaizdas, nustatomas krūtinės ląstos rentgeniniu tyrimu.

C. Pakitę spirometriniai rodikliai (restrikcinio pobūdžio), sumažèjusi dujų difuzija.

3. Bronchuc ir alveolių nuoplovose (BAL) limfocitozè:

A. Sumažèjęs CD4/CD8 santykis.

B. Antigeno sąlygotos limfocitu transformacijos teigiamas testas.

4. Teigiamas provokacinis inhaliuojamasis mėginys:

A. Kartotinè aplinkos veiksnių (alergenų) ekspozicija.

B. Provokacinis inhaliuojamasis mėginys naudojant specifinius antigenus (stacionaro sąlygomis).

5. Būdingi histologiniai pokyčiai:

A. Granuliomos be kazeozinès nekrozès arba

B. Vienabranduolių ląstelių infiltratai.

Diagnozė patvirtinama esant šioms sąlygoms:

- 1,2 ir 3 kriterijai, histologinis patvirtinimas nebūtinas.

- 1, 2 ir 4 A, gali reikèti bronchuc ir alveolių nuoplovu (BAL) tyrimo ar histologinio patvirtinimo.

- 1, 2 A, 3 ir 5 kriterijai.

- 2, 3 ir 5 kriterijai.

\section{GYDYMAS}

Pirmasis ir pagrindinis uždavinys gydant alerginị alveolitą - sąveikos su antigenu nutraukimas.

Sunkiais alerginio alveolito atvejais, dažniausiai poūmès ar lètinès eigos, progresuojant ligos simptomams, esant pakitusiems plaučių funkcijos rodikliams, hipoksemijai, radiologiniams pokyčiams plaučiuose, skirtinas gydymas gliukokortikoidais. Rekomenduojama geriamojo prednizolono skyrimo schema: 0,5-1 $\mathrm{mg} / \mathrm{kg}$ per parą (maksimali paros dozè - $60 \mathrm{mg}$ ) 1-2 sav.; dozè koreguojama mažinant per 2-4 sav. Palaikomasis gydymas gliukokortikoidais paprastai neski- riamas, derètų turèti omenyje ir galimas šalutines reakcijas.

Klinikiniu tyrimų, kuriuose būtú vertinamas alerginio alveolito gydymo efektyvumas, atlikta nedaug. Monkare su kolegomis tyrè 93 ligonius, turinčius „fermerio plaučius", kuriems gydyti 4 ar 12 sav. skyrè geriamujuc gliukokortikoidu arba nurode tik vengti kontakto su alergenu. Ligos simptomai greičiau išnyko gliukokortikoidais gydytų pacientų grupèje, tačiau, ịvertinus simptomus po 6 ménesių, reikšmingo skirtumo tarp grupių nenustatyta. Kitame tyrime, atliktame Kokkarinen ir kolegų, 36 asmenys, sergantys ūminès eigos „fermerio plaučiais“, 6 savaites buvo gydyti prednizolonu arba placebu. Po mènesio ištyrus dujų difuziją, geresni rodikliai nustatyti gydytiems gliukokortikoidais, tačiau, stebint rezultatus 5 metų laikotarpiu, reikšmingo skirtumo tarp grupių nebuvo.

Apibendrinant reikia pabrèžti, kad alerginis alveolitas dažniau būna kintamo intensyvumo, klinikinès išraiškos ir kintamos eigos sindromų rinkinys, o ne tolygi „vieno veido“ liga, todèl ir šios ligos diagnostika, gydymas turètų būti kompleksinis.

ALLERGIC ALVEOLITIS
BRIGITA ŠITKAUSKIENE
DEPARTMENT OF PULMONOLOGY AND IMMUNOLOGY
LITHUANIAN UNIVERSITY OF HEALTH SCIENCES
Keywords: allergic alveolitis, hypersensitivity pneumonitis.
Summary. Allergic alveolitis (also called hypersensitivity pneumonitis) is a
diffuse interstitial lung disease caused by hypersensitivity to inhaled antigenic
organic particles. In the present article clinically important aspects of allergic
alveolitis are reviewed.

\section{LITERATŪRA}

1. Mitchell RS, Kumar V, Abbas AK, Fausto N. Hypersensitivity pneumonitis. In Robbins Basic Pathology 2007. Philadelphia: Saunders; 8th edition, p.503.

2. Mohr LC. Hypersensitivity pneumonitis. Curr Opin Pulm Med 2004; 10: 401-11.

3. Ohtani Y, Saiki S, Kitaichi M, Usui Y, Inase N, Costabel U, Yoshizawa Y. Chronic bird fancier's lung: histopathological and clinical correlation. An application of the 2002 ATS/ERS consensus classification of the idiopathic interstitial pneumonias. Thorax 2005; 60: 665-71.

4. Camarena A, Juarez A, Mejia M, et al. Major histocompatibility complex and tumor necrosis factor-alpha polymorphisms in pigeon breeder's disease. Am J Respir Crit Care Med 2001; 163: 1528.

5. Hanak V, Golbin JM, Ryu JH. Causes and presenting features in 85 consecutive patients with hypersensitivity pneumonitis. Mayo Clin Proc 2007; 82: 812.

6. Selman M. Hypersensitivity pneumonitis: a multifaceted deceiving disorder. Clin Chest Med 2004; 25: 531.

7. Agostini C, Trentin L, Facco M, Semenzato G. New aspects of hypersensitivity pneumonitis. Curr Opin Pulm Med 2004; 10: 378.

8. King TE, Flaherty KR, Hollingsworth $\mathrm{H}$. Diagnosis of hypersensitivity pneumonitis. Up ToDate 2010; www.uptodate.com

9. Danila E, Šatkauskas B. Klinikinè pulmonologija, 2008. Vilnius: UAB "Vaistu žinios", trečiasis leidimas; 312-15. 